\title{
Association of Mean Platelet Volume in the Late First Trimester of Pregnancy and Development of Preeclampsia
}

\author{
Shailja S Bhamri ${ }^{1}$, Urmila Singh ${ }^{2}$, Seema Mehrotra ${ }^{3}$, Vandana Solanki $^{4}$
}

\begin{abstract}
Aim: The aim of the study was to find out the correlation between the mean platelet volume in the late 1st trimester of pregnancy and development of a Preeclampsia later on.

Materials and methods: It was a prospective cohort study in which 500 pregnant women (11-14 weeks of gestation) were enrolled and their mean platelet volume (MPV) was measured. They were followed till delivery. MPV of pre-eclamptic and normotensive women was compared. Results: MPV of pre-eclamptic women was significantly higher than that of the normotensive women $(p=0.001)$.

Conclusion: MPV >10.55 fL was found to be $68.7 \%$ sensitive and $55.9 \%$ specific for the prediction of Preeclampsia with a negative predictive value of $87.6 \%$.

Keywords: Mean platelet volume, Predictive value, Preeclampsia.

Journal of South Asian Federation of Obstetrics and Gynaecology (2019): 10.5005/jp-journals-10006-1672
\end{abstract}

\section{INTRODUCTION}

Preeclampsia is a pregnancy-specific syndrome characterized by hypertension and proteinuria developing after 20 weeks of gestation ${ }^{1}$ and it can affect virtually every organ system. It affects $5-10 \%$ of pregnancies worldwide ${ }^{2}$ and $4.6 \%$ of pregnancies in India. $^{3}$

Pregnancy is characterized by a physiological rise in the strain exerted upon the endothelium. Normal pregnancy is characterized by an increase in platelet aggregation and a decrease in the number of circulating platelets with gestation. The platelet lifespan declines and MPV increases minimally during pregnancy. ${ }^{4}$

The pathophysiology of Preeclampsia consists of endothelial cell damage and intravascular thrombin generation. This leads to increased platelet consumption, which directly causes an increase in the synthesis of platelets by the bone marrow. Platelet activation results in enhanced platelet synthesis, which directly causes an increase in MPV. ${ }^{5}$

\section{Aims and Objectives}

To find out the correlation between the MPV in late first trimester of pregnancy and development of Preeclampsia.

\section{Materials and Methods}

This Prospective Cohort study was conducted at the Department of Obstetrics and Gynecology in collaboration with the Department of Pathology, King George's Medical University.

An estimated 500 pregnant women with singleton pregnancy whose period of gestation was between 11 weeks and 14 weeks (confirmed by USG) attending the antenatal OPD of the Department of Obstetrics and Gynecology were enrolled in the study and $2 \mathrm{~mL}$ of venous blood was collected in EDTA vials. The samples were transported to the Department of Pathology within half an hour of their collection and were subjected to an automated cell counter for the estimation of mean platelet volume. Women with conditions such as hypertension, diabetes mellitus, collagen tissue disease,
${ }^{1-4}$ Department of Obstetrics and Gynecology, King George Medical University, Lucknow, Uttar Pradesh, India

Corresponding Author: Shailja S Bhamri, Department of Obstetrics and Gynecology, King George Medical University, Lucknow, Uttar Pradesh, India, Phone: +91 7054165714, e-mail: drshailja.gmch@ gmail.com

How to cite this article: BhamriSS, Singh U, Mehrotra S, et al. Association of Mean Platelet Volume in the Late First Trimester of Pregnancy and Development of Preeclampsia. J South Asian Feder Obst Gynae 2019;11(3):172-174.

Source of support: Nil

Conflict of interest: None

heart disease, renal disease, hepatic disease, and pregnancies with fetal chromosomal anomalies and congenital defects were excluded from the study. Women who developed any medical problem other than Preeclampsia during observation were also excluded from the study.

After making the necessary exclusions, the number of women left was 416 . They were divided into two groups: the study group and the control group. The study group comprised women who developed Preeclampsia. It was further divided into two sub-groups: Study group I (women who developed nonsevere Preeclampsia, $n=61$ ) and study group II (women who developed severe Preeclampsia, $n=22$ ). Preeclampsia was defined as per the ACOG 2013 Task Force Guidelines. The statistical analysis was done using Statistical Package for Social Sciences, version 15.0.

\section{Results}

Of the 416 women included in the study, 19.95\% developed preeclampsia. An estimated 61 women (14.66\%) developed a nonsevere preeclampsia, 22 women (5.29\%) developed a severe preeclampsia, and rest 333 (80.05\%) were normal healthy pregnant women. 
All the women enrolled in the study were demographically similar. The mean age of the women in this study was $25.85 \pm 2.84$ years. The mean age of the controls was $25.71 \pm 2.64$ years and that of the Study group was $26.43 \pm 3.47$ years.

The mean platelet volume of the control group was $10.71 \pm 1.81$ $\mathrm{fL}$. The mean platelet volume of the entire study group was $11.41 \pm$ $1.57 \mathrm{fL}$, while that of the study group I was $11.21 \pm 1.59 \mathrm{fL}$ and that of the study group II was $11.99 \pm 1.39 \mathrm{fL}$.

After statistical analysis, it was found that the MPV of the study group was significantly higher than that of the controls, with a $p$ value of 0.001 (Table 1). When the MPV of the study group I was compared with that of the controls, the $p$ value was found to be 0.044 (Table 2), which was also statistically significant. Table 3 shows that the MPV of the study group II was significantly higher than that of the controls ( $p=0.001$ ). The comparison of MPV of study group I and study group II is shown in Table 4, which shows that the MPV of study group II was significantly higher than that of the study group I $(p=0.045)$.

Area under curve was 0.638 (indicating a projected accuracy of $63.8 \%$ ) for MPV. On evaluating ROC (Fig. 1), a cutoff value of MPV $>10.550 \mathrm{fL}$ was predicted to be $68.7 \%$ sensitive and $55.9 \%$ specific. Its positive predictive value was $27.5 \%$ and negative predictive value was $87.6 \%$.

\section{Discussion}

Preeclampsia is a pregnancy-specific disorder characterized by the development of hypertension and proteinuria after 20 weeks of gestation. ${ }^{1}$ Impaired trophoblastic invasion of the maternal spiral arterioles during placentation has been postulated to be the etiopathogenesis of Preeclampsia. The resulting endothelial damage in the maternal spiral arterioles causes platelet consumption and, hence, platelet activation. Since placentation occurs mainly

Table 1: A comparison between MPV of the study group and that of the control group

\begin{tabular}{llll}
\hline & $\begin{array}{l}\text { Study group } \\
(n=83)\end{array}$ & $\begin{array}{l}\text { Control group } \\
(n=333)\end{array}$ & p value \\
\hline $\mathrm{MPV}(\mathrm{fL})($ mean $+\mathrm{SD})$ & $11.41 \pm 1.57$ & $10.71 \pm 1.81$ & 0.001 \\
\hline
\end{tabular}

Table 2: A comparison of MPV of study group I with that of the control group

\begin{tabular}{llll}
\hline & $\begin{array}{l}\text { Study group I } \\
(n=61)\end{array}$ & $\begin{array}{l}\text { Control group } \\
(n=333)\end{array}$ & p value \\
\hline MPV (fL) (mean + SD) & $11.21 \pm 1.59$ & $10.71 \pm 1.81$ & 0.044 \\
\hline
\end{tabular}

Table 3: A comparison of MPV of study group II with that of the control group

\begin{tabular}{llll}
\hline & $\begin{array}{l}\text { Study group II } \\
(n=22)\end{array}$ & $\begin{array}{l}\text { Control group } \\
(n=333)\end{array}$ & pvalue \\
\hline $\mathrm{MPV}(\mathrm{fL})($ mean $+\mathrm{SD})$ & $11.99 \pm 1.39$ & $10.71 \pm 1.81$ & 0.001 \\
\hline
\end{tabular}

Table 4: A comparison of MPV of study group II with that of study group I

\begin{tabular}{llll}
\hline & $\begin{array}{l}\text { Study group II } \\
(n=22)\end{array}$ & $\begin{array}{l}\text { Study group I } \\
(n=61)\end{array}$ & p value \\
\hline MPV (fL) (mean + SD) & $11.99 \pm 1.39 \mathrm{fL}$ & $11.21 \pm 1.59$ & 0.045 \\
\hline
\end{tabular}

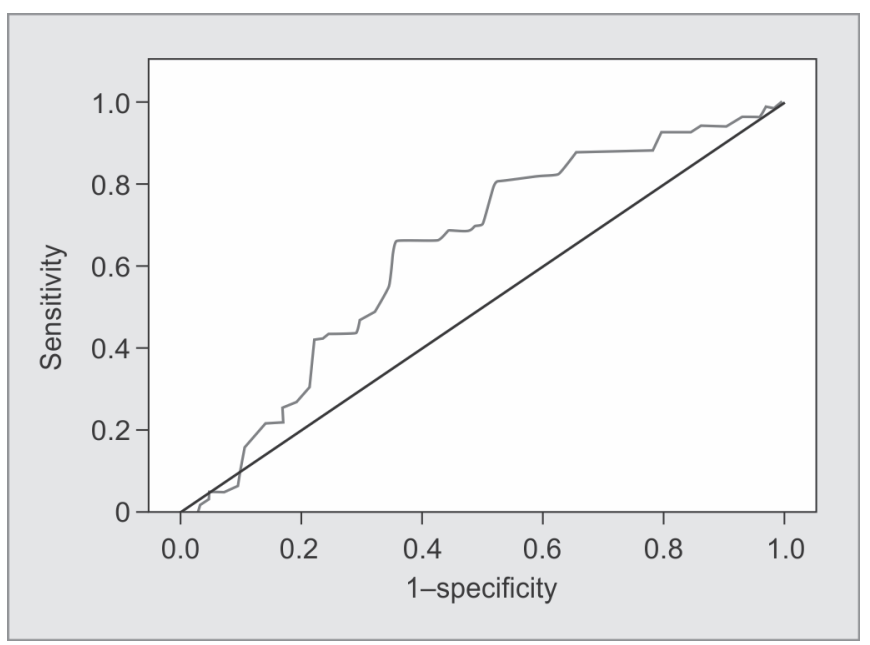

Fig. 1: Receiver operating characteristic

in the late first trimester, the present study aimed to study the co-relation between the MPV recorded between 11 and 14 weeks and development of a Preeclampsia later on.

A glance at the literature shows conflicting results over the role of platelet indices in predicting a Preeclampsia.

Study done by Freitas et al..$^{6}$ showed that the MPV was higher in patients with severe Preeclampsia when compared to the normotensive pregnant and nonpregnant women. The $p$ values for these findings were 0.05 and $<0.001$, respectively, showing that these values were statistically significant.

Annam et al. ${ }^{1}$ showed that the value of MPV was $8.63 \pm$ $1.32 \mathrm{fL}$ in the normotensive women, $10.38 \pm 1.65 \mathrm{fL}$ in the preeclamptic group, and $11.03 \pm 2.23 \mathrm{fL}$ in the eclamptic group. They concluded that there occurs a gradual increase in the MPV from the normotensive pregnant women to the pre-eclamptic and eclamptic women and the differences were statistically significant.

In the present study, the results obtained were similar to the earlier cited studies. The MPV of the study group is $11.41 \pm 1.57 \mathrm{fL}$ and that of the controls is $10.71 \pm 1.81 \mathrm{fL}$. The $p$ value is 0.001 . Hence, it is obvious that the present study shows a statistically significant difference between the MPV values of the study group and those of the control group.

A study done by Kanat-Pektas et al. ${ }^{5}$ also arrived the same result. In their study, the MPV of the uncomplicated pregnancies was $10.2 \pm 0.9 \mathrm{fL}$ and that of the preeclamptic women was $11.0 \pm$ $1.2 \mathrm{fL}$. Thus, the results of the present study are quite comparable to their results.

When we analyze the MPV values of the different subgroups in the present study, we find that the MPV of the study group I is 11.21 $\pm 1.59 \mathrm{fL}$, the mean MPV of the study group II is $11.99 \pm 1.39 \mathrm{fL}$, and that of the controls is $10.71 \pm 1.81 \mathrm{fL}$. A cross-sectional study done by Ammar et al. ${ }^{7}$ showed that the MPV of normotensive pregnant women, mildly preeclamptic women, and severely preeclamptic women were $8.522 \pm 0.8555 \mathrm{fL}, 9.843 \pm 0.7008 \mathrm{fL}$, and $11.294 \pm$ $1.1714 \mathrm{fL}$, respectively. The difference in the mean MPV values of the different groups in the present study as well as in their study was statistically significant. Hence, their results also laid stress upon the fact that the MPV in late 1st trimester is higher in women destined to develop Preeclampsia and can be used as a predictive marker. They also concluded that MPV value of $10.3 \mathrm{fL}$ can predict Preeclampsia with $87.5 \%$ sensitivity and $85.3 \%$ specificity. 
The results of the present study are also well supported by the findings of Dadhich et al., ${ }^{8}$ who found that the MPV of the pre-eclamptic women was significantly more than that of the normotensive women at all periods of gestation.

The present study is also in agreement with the observations made by Santos et al. ${ }^{9}$ and Mondal et al. ${ }^{10}$

The MPV values obtained in the study of Mondal et al. ${ }^{10}$ were $10.05 \pm 0.71 \mathrm{fL}, 11.55 \pm 0.86 \mathrm{fL}$, and $12.16 \pm 1.05 \mathrm{fL}$ in normal pregnancy, patients with Preeclampsia and eclampsia, respectively. Hence, their conclusion that the MPV is higher in preeclamptic and eclamptic women than normotensive women supports the observations and results of the present study.

Kashanian et al. ${ }^{11}$ also found that the MPV in the 1 st trimester of pregnancy in preeclamptic women was higher $(10.2 \pm 1.06 \mathrm{fL})$ when compared to the normal pregnant women $(9.68 \pm 1.09 \mathrm{fL})$, $p=0.008$. Hence, their findings were also consistent with the results of the present study.

Ceyhan et al. ${ }^{12}$ conducted a study in which they found that in the first trimester, the MPV of the controls were $9.45 \pm 1.11 \mathrm{fL}$, that of the mildly preeclamptic group was $9.18 \pm 1.52 \mathrm{fL}$, and that of the women with severe Preeclampsia was $8.87+1.79 \mathrm{fL}$. They did not find any statistically significant difference between the MPV of the control group and the pre-eclamptic group. Hence, their results do not correlate with the results of the present study.

This could be due to a difference in the method of MPV estimation and a difference in the demographic characteristics of the population.

\section{Conclusion}

From the earlier mentioned observations, we conclude that the mean platelet volume increases in the late first trimester (11-14 weeks) in women destined to develop a Preeclampsia. Also, it can be inferred that the mean platelet volume increases more in the women who are predisposed to develop a severe Preeclampsia $(11.99 \pm 1.39 \mathrm{fL})$ than those who will develop a nonsevere Preeclampsia (11.21 $\pm 1.59 \mathrm{fL})$. Since the negative predictive value came out to be $87.6 \%$, the estimation of MPV in the late first trimester of pregnancy can be used to identify women who need to be followed up carefully for the development of Preeclampsia later on in pregnancy. We propose that further studies with a large sample size be done to study the combination of mean platelet volume with other economical markers so that Preeclampsia can be predicted with increased sensitivity and specificity without putting extra monetary burden on the pregnant women especially in low-resource settings.

\section{References}

1. Annam V, Srinivasa K, et al. Evaluation of platelet indices and platelet counts and their significance in pre-eclampsia and eclampsia. Int J Biol Med Res 2011;2(1):425-428.

2. Cunningham FG, Lenovo KJ, et al. Williams Obstetrics, 24th ed., United States of America: McGraw-Hill Education; 2014. pp. 728-779.

3. Bilano VL, Ota E, et al. Risk Factors of Pre-Eclampsia/Eclampsia and Its Adverse Outcomes in Low- and Middle-Income Countries: A WHO Secondary Analysis. PLoS One 2014;9(3):e91198. DOI: 10.1371/journal. pone.0091198.

4. Juan P, Stefano G, et al. Platelets in pregnancy. J Perinat Med 2011;5(4):90.

5. Kanat-Pektas M, Yesildager U, et al. Could mean platelet volume in late first trimester of pregnancy predict intrauterine growth restriction and pre-eclampsia? J Obstet and Gynaecol Res 2014; 40(7):1840-1845. DOI: 10.1111/jog.12433.

6. Freitas LG, Alpoim PN, et al. Preeclampsia: Are platelet count and indices useful for its prognostic? Hematology 2013;18(6):360-364. DOI: 10.1179/1607845413Y.0000000098.

7. Kamel Ammar WA, El MA, et al. Evaluation of platelet indices and their significance in Preeclampsia. Nature and Science 2014;12(3): 147-153.

8. Dadhich S, Agrawal S, et al. Predictive value of platelet indices in development of preeclampsia. J Safog 2012;4(1):17-21. DOI: 10.5005/ jp-journals-10006-1164.

9. Santos EV, Meirelles Filho J. Measurement of platelet parameters in normal and preeclamptic pregnant women. Revista Brasileira de Ginecologia e Obstetrícia 2004;26(3):201-206.

10. Mondal BR, Paul D, et al. Assessment of platelet count and platelet indices in pre-eclampsia and eclampsia. Am J Innov Res Appl Sci 2015;1(3):80-84.

11. Kashanian M, Hajjaran M, et al. Evaluation of the value of the first and third trimester maternal mean platelet volume (MPV) for prediction of pre-eclampsia. Pregnancy Hypertens 2013;3(4):222-226. DOI: 10.1016/j.preghy.2013.06.001.

12. Ceyhan T, Beyan C, et al. The effect of pre-eclampsia on complete blood count, platelet count and mean platelet volume. Ann Hematol 2006;85(5):320-322. DOI: 10.1007/s00277-006-0091-7. 